\title{
Saúde, ecologia de saberes e estudos de impactos ambientais de refinarias no Brasil
}

José Marcos da Silva ${ }^{(a)}$

Idê Gomes Dantas Gurgel(b)

Lia Giraldo da Silva Augusto(c)

Silva JM, Gurgel IGD, Augusto LGS. Health, ecology of knowledge and environmental impact studies on oil refineries in Brazil. Interface (Botucatu). 2016; 20(56):111-22.

This paper presents an analysis on environmental impact studies on oil refineries. Critical analysis on public health was undertaken with a view to proposing an ecology of knowledge that would form an alternative to the traditional model for knowledge construction within the environmental licensing process. This was a qualitative study using document analysis to gather data, and thematic content analysis to assess the results. It was noted that in the traditional mode, there was fragmentation, reductionism, conceptual disconnection, omission of complex realities and silence regarding important issues relating to guaranteed rights, health and complaints about environmental conflicts. It was concluded that development of environmental impact studies provides an opportunity for practicing ecology of knowledge through production of knowledge shared with social movements. This should translate into an instrument for defense of life, with a view to action promoting public health and environmental protection.

Keywords: Health. Environment. Ecology of knowledge. Petroleum industry.
Este artigo apresenta uma análise de estudos de impactos ambientais de refinarias de petróleo. Realizou-se uma análise crítica sobre a saúde coletiva com vistas a propor uma ecologia de saberes alternativa ao modelo tradicional de construção de conhecimento no processo de licenciamento ambiental. Pesquisa qualitativa que utilizou a análise documental, para a coleta de dados, e a análise de conteúdo temático, para a análise dos resultados. Verifica-se que, no modo tradicional, há: fragmentação, reducionismo, desarticulação conceitual, omissão de realidades complexas, silenciamento sobre aspectos importantes para a garantia de direitos, saúde e denúncia de conflitos ambientais. Concluise que a elaboração de estudos de impactos ambientais é uma oportunidade para a prática da ecologia de saberes por meio da produção de conhecimentos compartilhada com os movimentos sociais, devendo traduzir-se em instrumento de defesa da vida, com vistas a ações de saúde coletiva e de proteção do ambiente.

Palavras-chave: Saúde. Ambiente. Ecologia de saberes. Insdústrias petroquímicas.

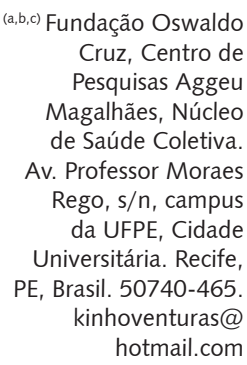
Cruz, Centro de Pesquisas Aggeu Magalhães, Núcleo de Saúde Coletiva. Av. Professor Moraes Rego, s/n, campus da UFPE, Cidade Universitária. Recife, PE, Brasil. 50740-465. kinhoventuras@ hotmail.com 


\section{Introdução}

A defesa do ambiente está relacionada à proteção da saúde humana, como prevista na Constituição Federal de 1988 e na Política Nacional de Meio Ambiente1. O principal procedimento para o licenciamento de empreendimentos tem sido os Estudos de Impactos Ambientais (EIAs), cujo objetivo é considerar a viabilidade, ou não, frente aos potenciais impactos biológicos, sociais, culturais e ambientais ${ }^{2}$.

Autores estudaram EIAs no campo da saúde coletiva, discutindo a produção de conhecimento sobre os riscos, e ressaltaram que os aspectos de saúde devem ser considerados para a elaboração de propostas e solução de problemas gerados ${ }^{3-9}$.

Nesse sentido, a Avaliação de Equidade Ambiental representa uma prática de democratização dos procedimentos de avaliação de impacto participativa proposta pela Rede Brasileira de Justiça Ambiental (RBJA), destacando que é necessário superar a elaboração dos ElAs responsável como função burocrática e figurativa, incapaz de deter qualquer empreendimento impactante do ponto de vista ambiental e social, servindo, muito mais, para angariar legitimidade sociopolítica ${ }^{10}$.

Discussões sobre a inserção da análise de saúde nos EIAs vêm produzindo algumas mudanças, como a portaria conjunta do Instituto Brasileiro de Meio Ambiente e Recursos Naturais Renováveis (Ibama), portaria n. 259/2009, que obriga a inserção das questões relacionadas à saúde do trabalhador nos EIAs ${ }^{11}$.

De modo semelhante, o artigo $23^{\circ}$ da Constituição Federal de 1988 e a lei 6.938 foram atualizados com a Lei Complementar n. 140, de 8 de dezembro de 2011, fixando normas para a cooperação entre os entes federados nas questões de proteção ambiental ${ }^{12}$.

Essas mudanças são oportunas, no momento de expansão da cadeia produtiva de petróleo no Brasil, que tem sido reconhecida por afetar a qualidade do ar, da água, do solo, e afetar os seres vivos ${ }^{13}$.

Em relação à saúde, essa cadeia produtiva está relacionada com: o aumento de câncer, o incremento das doenças neurológicas e psíquicas, das doenças de pele, do fígado, cardiovasculares, doenças respiratórias, os acidentes de construção, operação, manutenção, acidentes típicos de trabalho, acidentes químicos ampliados, que colocam em risco populações que vivem nos contornos dos empreendimentos ${ }^{14-19}$.

Essa problemática pode ser melhor compreendida a partir de experiências, como a da região do entorno da Refinaria Presidente Bernardes, em Cubatão, conhecida como "Vale da Morte", que, nos anos de 1970 e 1980, representava símbolo da poluição industrial no país ${ }^{19}$. A poluição gerada atingia níveis alarmantes, que provocavam doenças respiratórias na população, além de casos de bebês nascidos com má-formação ${ }^{20}$. Essa experiência contribui para contextualização de mudanças ecológicas introduzidas por novas refinarias $5,21,22$.

Santos ${ }^{21}$ propõe a superação do "pensamento abissal" e sua soberania epistêmica, vindo da ciência moderna eurocêntrica, de declarada lógica dicotômica que exclui outras formas de saberes que não se encaixam nos critérios de objetividade e linearidade. Isso se daria por meio da "ecologia de saberes", que parte do reconhecimento de outros saberes, além do científico.

A ecologia de saberes suscita um conjunto de ideias e imagens teóricas em que a mistura dos saberes e o diálogo entre eles se deslocam para o centro. O diálogo da pluralidade de saberes deve ser construído a partir do encontro de saberes, sejam eles não hegemônicos ou hegemônicos ${ }^{21}$.

Para Nunes ${ }^{23}$, ecologia de saberes concebe a construção de conhecimento a partir da experiência do mundo dos oprimidos; e o critério de avaliação de um dado conhecimento depende do modo como ele afeta a existência dos povos envolvidos numa práxis indissociável da produção, avaliação e legitimação pelos sujeitos interessados. Justifica-se por considerar que as experiências de vida dos oprimidos lhes são inteligíveis, sob a crença de que as consequências nefastas possam ser previsíveis e controláveis ${ }^{21,23}$.

Paulo Freire, Milton Santos, Eduardo Galeano e Enrique Dussel também defenderam formulações teóricas que assumam posições críticas quanto à prática de produção de conhecimento, propondo outro modo, que seja implicada à realidade da vida social das pessoas, para ajudar a transformá-las ${ }^{22,23}$. 
No que se refere ao desenvolvimento da ecologia de saberes, Freitas e Porto ${ }^{24}$ analisaram contribuições de Boaventura de Sousa Santos para a saúde coletiva. Ressaltam sua importância, sobretudo, para as práticas de construção compartilhada do conhecimento, entendida como algo a ser construído pelos sujeitos em seus locais, em suas experiências cotidiana, compreendidas em articulação com ações sociais e coletivas.

Giatti, Landin e Toledo ${ }^{25}$ realizaram revisão da produção acadêmica sobre a aplicabilidade da ecologia de saberes na saúde e constataram tímida permeabilidade.

O Dossiê Abrasco - um alerta sobre os impactos dos agrotóxicos na saúde -, pode ser considerado uma experiência virtuosa de produção baseada na ecologia de saberes. Trata-se do resultado de uma articulação entre redes de movimentos sociais e pesquisadores da Associação Brasileira de Saúde Coletiva, que interagiram para resistir aos efeitos do uso dos agrotóxicos na saúde humana, exigindo maior atuação do Estado brasileiro na garantia do direito à saúde ${ }^{26}$.

O presente estudo não realizou uma ecologia de saberes, pois, para isso, seria necessária a incorporação das comunidades atingidas nos territórios e movimentos sociais envolvidos, mas uma análise crítica com vistas a propor uma ecologia de saberes como alternativa ao modelo tradicional de elaboração de EIAs de refinarias de petróleo no Brasil.

\section{Método}

Desenvolveu-se um estudo de casos, no período de março de 2013 a abril de 2014, com o objetivo de realizar um julgamento ex-post de uma intervenção. $O$ estudo de casos costuma ser a primeira abordagem de um tema ainda pouco conhecido e cujas características ou variações não foram convenientemente detalhadas. Apesar de limitar-se a conclusões específicas, pequenas inferências e explicações, tal método permite, percorrendo-o, generalizações que poderão servir de fundamentos para novas teorias ${ }^{27}$.

Seguiram-se três caminhos metodológicos: 1 análise do tema saúde coletiva nos EIAs; 2 análise crítica do modelo tradicional de elaboração dos EIAs; 3 proposição de perspectivas alternativas com base na ecologia de saberes.

Para todos os caminhos metodológicos, adotou-se a análise de conteúdo temático, técnica de pesquisa para descrição objetiva, sistemática e qualitativa do conteúdo manifesto das comunicações, que tem por fim interpretá- $\operatorname{los}^{28}$.

A análise de conteúdo temático em três etapas: pré-análise - leitura de primeiro plano para atingir um nível mais aprofundado; exploração do material - codificação, categorização e inferência; interpretação - análise dos significados dos enunciados que determinam suas características.

A definição das categorias analíticas, deu-se por elementos de conteúdo agrupados por sentido, por meio do modelo aberto em que as categorias não são fixas no início, mas tomam forma no curso da análise ${ }^{29}$.

Adotou-se o software QSR Nvivo 2.0 para criar as categorias e facilitar a releitura de textos, permitindo, ao pesquisador, operar e agrupar a diversidade de dados que mantinham algo em comum em relação ao tema ${ }^{28}$.

Procedeu-se a um levantamento bibliográfico, utilizando as bases bibliográficas: Lilacs-Bireme, PubMed-MEDLINE e SciELO. As palavras-chave utilizadas em português foram: ecologia de saberes, saúde, ambiente e determinação social da saúde, com adição de termos correspondentes à refinaria de petróleo, impactos ambientais, licenciamento, estudos de impactos ambientais.

A seguir, são descritos os caminhos metodológicos:

1 Análise do tema saúde coletiva: foram escolhidos, por conveniência, os EIAs das refinarias de Paulínia, em Campinas/SP; refinaria Abreu e Lima, em Ipojuca/PE; do Complexo Petroquímico do Rio de Janeiro, em Itaboraí/RJ. Emergiram as seguintes categorias: equipe profissional, aspectos ambientais, aspectos populacionais, custos socioambientais e aspectos de saúde. Os EIAs são documentos de domínio público, disponibilizados pelo IBAMA e nas agências estaduais de meio ambiente. 
2 Análise crítica ao modelo tradicional de elaboração: para cada categoria que emergiu da análise do tema saúde coletiva, foram realizadas críticas ao modelo tradicional de construção de conhecimento dos EIAs, a partir do marco teórico conceitual levantado.

3 Proposição de perspectivas alternativas para a ecologia de saberes: a partir do levantamento bibliográfico e da análise crítica ao modelo tradicional de elaboração dos EIA, foram identificadas perspectivas para a ecologia de saberes em inter-relação com a saúde coletiva.

\section{Resultados e discussão}

No Quadro 1, estão: os resultados sobre equipe profissional, a análise crítica ao modelo tradicional de construção de conhecimento dos EIAs e as perspectivas alternativas para a ecologia de saberes.

Quanto à equipe profissional, emerge a ideia de um grupo de profissionais que se reúne para apresentar pareceres restritos aos seus campos disciplinares ou especialidades.

Verifica-se que não há trabalho interdisciplinar. Isso parece dificultar a formulação de explicações próximas da realidade complexa que envolve a implantação de refinarias.

A perspectiva crítica considera o processo de elaboração dos EIAs como um processo interdisciplinar capaz de produzir uma análise de impactos correlacionando diversos campos disciplinares e diversos saberes, evidenciando conexões entre eles, de modo a produzir informações úteis à proteção da saúde e do ambiente. O modo tradicional de produção das informações nos EIAs, prejudica a articulação entre as dimensões de saúde e de ambiente.

Os especialistas informam sobre aspectos da realidade de forma fragmentada, sem considerar como o processo de implantação de uma refinaria modifica os territórios. Assim, contrariam a recomendação de que as análises sejam realizadas por equipe multiprofissional, capaz de valorar as relações do ambiente e da saúde, considerando mudanças no perfil epidemiológico e impactos ao sistema de saúde, antecipando mudanças na morbimortalidade dos grupos vulneráveis ${ }^{13}$.

É imprescindível a participação de profissionais capazes de: avaliar situações e riscos de adoecimento, realizar planejamento estratégico situacional, apontar prioridades para a vigilância em saúde, com vistas à promoção da saúde. Ademais, avaliar o impacto na seguridade social pelos custos e anos potenciais de vidas perdidos pelos acidentes de trabalho e acidentes químicos ampliados ${ }^{9,12,17}$.

As equipes de consultores são compostas por profissionais especialistas contratados pelos empreendimentos. Essa realidade está relacionada à falta de autonomia das consultorias e dos profissionais contratados pelos empreendimentos interessados no licenciamento. Ademais, há a falta de capacitação dos órgãos licenciadores e assimetria de recursos das populações atingidas para a produção de contrapareceres e contraexpertise ${ }^{6,7}$.

Quanto às bases de conhecimento da equipe, constata-se o predomínio de engenheiros e de biólogos. As considerações sobre a saúde não são realizadas a partir da interface com o ambiente, a produção, o trabalho e as tecnologias ${ }^{6-8}$.

O que se sobressai é a forma de conceber a avaliação dos impactos ambientais, sem levar em consideração os diversos campos de saberes próprios da saúde coletiva. Assim, produz-se um conhecimento enviesado e há ocultação de situações de risco que acabam por desfavorecer os grupos humanos vulneráveis ${ }^{17,18}$.

Ademais, inexiste um sistema de informação em saúde que possibilite a qualidade das informações sobre os contextos de cenários prospectivos de situações de risco envolvendo o refino de petróleo.

A complexidade envolvida nesses contextos e processos exige a integração de saberes e a utilização de múltiplos métodos de diversos campos das ciências humanas, da saúde coletiva, das ciências ambientais, das engenharias, considerando os contextos de vida das comunidades e a saúde coletiva ${ }^{24}$.

Segundo $\mathrm{Luz}^{30}$, o olhar sobre a complexidade, buscado pela saúde coletiva, exige abordagens multidisciplinares, interdisciplinares e transdisciplinares. A ecologia de saberes desponta como potente para produzir conhecimento a partir da problematização e da inclusão daqueles que vivenciam o mundo real em que, de fato, os fenômenos ocorrem. É uma concepção que propõe a integração de saberes técnicos, científicos e populares ${ }^{21,22,24}$. 
Essa perspectiva favorece apreender e interpretar o processo saúde-doença e desenvolver novas tecnologias de intervenção condizentes com as demandas sociais, legitimadas pelos movimentos sociais $^{10,26,30,31}$.

Quadro 1. Equipe profissional nos EIAs, a análise crítica ao modelo tradicional de construção de conhecimento dos EIAs e as perspectivas alternativas para a ecologia de saberes, Brasil, 2014

\begin{tabular}{|c|c|c|c|}
\hline Categoria & $\begin{array}{l}\text { Conteúdos temáticos } \\
\text { extraídos dos EIA }\end{array}$ & $\begin{array}{l}\text { Análise crítica ao modelo } \\
\text { tradicional de construção de } \\
\text { conhecimento dos EIAs }\end{array}$ & $\begin{array}{l}\text { Perspectivas alternativa } \\
\text { para a ecologia de saberes }\end{array}$ \\
\hline $\begin{array}{c}\text { Equipe } \\
\text { profissional }\end{array}$ & $\begin{array}{l}\text { Diferentes profissionais } \\
\text { contratados para apresentar } \\
\text { parecer sobre os impactos } \\
\text { a partir de elementos do } \\
\text { campo disciplinar de cada } \\
\text { um; } \\
\text { A metodologia de trabalho } \\
\text { é fixada com vista a cumprir } \\
\text { o termo de referência, } \\
\text { não abordando o que } \\
\text { deve ser observado pelos } \\
\text { especialistas; } \\
\text { As conclusões dos ElA são } \\
\text { baseadas, unicamente, } \\
\text { nas experiências dos } \\
\text { especialistas com } \\
\text { predomínio de engenheiros } \\
\text { civis, engenheiros químicos, } \\
\text { engenheiros de produção, } \\
\text { físicos e biólogos - } \\
\text { engenharias e biologia. }\end{array}$ & $\begin{array}{l}\text { Desarticulação dos especialistas } \\
\text { em torno de um problema comum, } \\
\text { não funcionando como equipe } \\
\text { integrada que atua conjuntamente. } \\
\text { A interdisciplinaridade não está } \\
\text { incorporada; } \\
\text { Não realizam procedimentos } \\
\text { metodológicos para abordar as } \\
\text { realidades sociais, incluindo a saúde } \\
\text { em suas múltiplas dimensões, o que } \\
\text { exigiria profissionais do campo da } \\
\text { saúde coletiva; } \\
\text { As referências utilizadas em geral não } \\
\text { se baseiam em estudos e pesquisas } \\
\text { amplas que incluem os vários campos } \\
\text { de saberes, inclusive os da saúde } \\
\text { coletiva. } \\
\text { A qualidade do ElAs fica } \\
\text { comprometida quando comparada } \\
\text { com a literatura especializada. }\end{array}$ & $\begin{array}{l}\text { Integração de profissionais que elaboram } \\
\text { correlações e colocam em evidências as } \\
\text { conexões entre as diversas considerações, } \\
\text { integrando suas atividades e discutindo } \\
\text { saberes. } \\
\text { Os impactos à saúde são identificados por } \\
\text { profissionais com qualificação técnica em } \\
\text { saúde coletiva que utilizem a abordagem } \\
\text { da saúde ambiental na perspectiva da } \\
\text { teoria da complexidade contemplando } \\
\text { a inter-relação dos processos produtivos } \\
\text { com o ambiente e a saúde. } \\
\text { Os métodos de pesquisa e o referencial } \\
\text { teórico das ciências humanas e da saúde } \\
\text { são empregados nos ElAs em triangulação } \\
\text { para responder a complexidade dos } \\
\text { impactos na vida e trabalho da população. } \\
\text { Os movimentos sociais participam da } \\
\text { produção, aprovação e legitimação do } \\
\text { conhecimento como sujeitos de pesquisa. }\end{array}$ \\
\hline
\end{tabular}

No Quadro 2, são apresentados os resultados relativos aos aspectos ambientais e aos aspectos demográficos. Esses são aspectos estratégicos para se pensar uma abordagem integrada de saúde e ambiente.

Verifica-se que o conceito de ambiente, que emerge dos EIAs, refere-se aos aspectos físicos da área geográfica a ser afetada pelo empreendimento, correspondendo às áreas de influência direta que compreende uma faixa ao longo das vias de suprimento de matérias-primas. O ambiente fica reduzido ao físico, no qual intensidade e magnitude dos impactos incidem direta ou indiretamente ${ }^{32}$. Além disso, limita-se ao político-administrativo dos municípios e do entorno do empreendimento, desconsiderando o potencial de transferência de nocividades entre municípios, estados e regiões geográficas.

Os aspectos ambientais e demográficos distanciam-se das discussões que se voltam para o conceito de território, que internaliza informações acerca: da história, dos grupos populacionais, das forças políticas, das redes sociais e técnicas, dos ecossistemas, do qual o ser humano faz parte ${ }^{10}$.

Reduzir o ambiente apenas ao aspecto físico representa não incorporar os conflitos. Por exemplo, nos EIAs, não há referências a processos de dominação política e expropriação econômica. Também não são referidos os conflitos por questões fundiárias, envolvendo povos tradicionais (indígenas, pescadores, ribeirinhos, quilombolas, posseiros), especuladores de terra e empresários.

A perspectiva para a ecologia de saberes utiliza-se de informações sobre características das diferentes comunidades existentes e suas vulnerabilidades, suas histórias, a distribuição 
populacional, atividades econômicas desenvolvidas, e os projetos locais de desenvolvimento sustentável, as relações sociais e culturais e suas interfaces com o ecossistema ${ }^{21-24}$.

Uma iniciativa que pode ser considerada uma ação baseada na ecologia de saberes tem sido a da RBJA que, em articulação com a Fundação Oswaldo Cruz, mantém o mapa de conflitos envolvendo injustiça ambiental e saúde no Brasil, colocando, em evidência, os territórios onde existem conflitos e injustiças praticados por empreendimentos ${ }^{33}$.

Esse mapa torna-se fundamental ao processo de licenciamento ambiental, pois revela conflitos e torna visíveis grupos vulneráveis que devem ser considerados na realização da avaliação de impactos ambientais, com vistas à garantia de proteção de seus direitos constitucionais.

Existe uma tensão entre os interesses de governos, empresários, investidores financeiros ${ }^{34}$ e os interesses dos povos tradicionais ${ }^{32}$. Esses são desconsiderados nos ElAs. Revelar os diferentes interesses permite que a sociedade possa participar da discussão sobre o licenciamento, ou não, de forma minimamente esclarecida, podendo posicionar-se sobre a violação dos direitos de grupos sociais mais vulneráveis.

Diversos autores concordam que as decisões relativas à complexidade dos conflitos ambientais perpassam o reconhecimento do caráter inseparável do ambiente em relação às pessoas que nele vivem e dele dependem para sua reprodução e metabolismo social ${ }^{32,33}$.

As comunidades, nos seus territórios, têm o direito a uma vida saudável. Por isso, os ElAs são importantes para a prevenção de danos à saúde dos grupos humanos vulneráveis, provendo medidas de redução das nocividades advindas dos artefatos técnicos e dos perigos ambientais decorrentes da poluição produzida pelas refinarias de petróleo ${ }^{20}$.

Quadro 2. Aspectos ambientais e demográficos nos EIAs, a análise crítica ao modelo tradicional de construção de conhecimento dos ElAs e as perspectivas alternativas para a ecologia de saberes, Brasil, 2014

\begin{tabular}{|c|c|c|c|}
\hline Categoria & $\begin{array}{l}\text { Conteúdos temáticos } \\
\text { extraídos dos EIA }\end{array}$ & $\begin{array}{l}\text { Análise crítica ao modelo } \\
\text { tradicional de construção de } \\
\text { conhecimento dos EIAs }\end{array}$ & $\begin{array}{l}\text { Perspectivas alternativa } \\
\text { para a ecologia de saberes }\end{array}$ \\
\hline $\begin{array}{l}\text { Aspectos } \\
\text { ambientais }\end{array}$ & $\begin{array}{l}\text { Correspondem aos limites da } \\
\text { área geográfica a ser direta ou } \\
\text { indiretamente afetada pelos } \\
\text { impactos - Áreas de influência } \\
\text { direta e indireta. }\end{array}$ & $\begin{array}{l}\text { Ausência de aspectos } \\
\text { sócioantropológicos e culturais } \\
\text { que formam os contextos, } \\
\text { onde estão os conflitos entre os } \\
\text { desenvolvimentistas, produtivistas e } \\
\text { comunidades como um todo, como } \\
\text { apontam pensadores da geografia } \\
\text { crítica. }\end{array}$ & $\begin{array}{l}\text { O ambiente é considerado como uma } \\
\text { dimensão inseparável dos sujeitos } \\
\text { que nele vivem e dele dependem } \\
\text { para a sua reprodução social, } \\
\text { conformada pelas reproduções bio- } \\
\text { comunal, de consciência, de conduta, } \\
\text { econômica, política e ecológica. }\end{array}$ \\
\hline $\begin{array}{c}\text { Aspectos } \\
\text { demográficos }\end{array}$ & $\begin{array}{l}\text { As populações habitantes dos } \\
\text { territórios são consideradas } \\
\text { unicamente a partir de } \\
\text { dados numéricos referentes } \\
\text { à contagem populacional do } \\
\text { setor censitário do IBGE. } \\
\text { Apenas as organizações sociais } \\
\text { formais são consideradas } \\
\text { como "proprietários" ou "não } \\
\text { proprietários" de terras. } \\
\text { Considerações genéricas } \\
\text { a respeito do crescimento } \\
\text { populacional - migração, } \\
\text { frequentemente associado à } \\
\text { geração de empregos. }\end{array}$ & $\begin{array}{l}\text { Não elaboram, não sistematizam, } \\
\text { não colidem e nem organizam } \\
\text { informações sobre os grupos sociais } \\
\text { e as intervenções que alterarão seus } \\
\text { modos de vida. } \\
\text { O uso de categorias físico espaciais, } \\
\text { sem qualquer consideração em } \\
\text { relação às populações humanas, cuja } \\
\text { realidade sociológica ultrapassa o } \\
\text { físico geográfico. } \\
\text { Não sistematizam a estimativa } \\
\text { da população residente, bem } \\
\text { como, os dados mais elementares } \\
\text { de população, como: população } \\
\text { economicamente ativa, profissão e } \\
\text { pirâmide etária. }\end{array}$ & $\begin{array}{l}\text { São utilizadas análises sócio- } \\
\text { antroplógicas e cultural da } \\
\text { população. } \\
\text { Estudos de cenários do processo de } \\
\text { migração e ocupação dos territórios } \\
\text { tendo como referência outros pólos } \\
\text { industriais e as consequências para a } \\
\text { saúde coletiva. } \\
\text { Uso de categorias sociais e } \\
\text { antropológicas e suas relações } \\
\text { com a saúde coletiva identificando } \\
\text { vulnerabilidades. }\end{array}$ \\
\hline
\end{tabular}


No que se refere aos aspectos demográficos, há um reducionismo ao tratar das populações, habitantes do espaço geográfico, apenas como referência a valores numéricos do setor censitário.

$\mathrm{Na}$ concepção da ecologia de saberes, pode-se afirmar que, as informações censitárias dão espaço para aspectos das relações sociais, e das identidades histórico-culturais. Nos EIAs, apenas as organizações sociais formais são reconhecidas como detentoras de direitos por danos causados pelo empreendimento.

O que se encontra nos EIAs são informações genéricas sobre a dinâmica populacional, sem projeções de crescimento populacional em decorrência do fluxo migratório ocasionado pela busca de oportunidade nos locais onde são implantadas as refinarias. Como alternativa, propõe-se produzir informações necessárias sobre grupos sociais, utilizando categorias sociológicas e antropológicas em suas relações com a saúde coletiva, como a identificação de populações em situação de vulnerabilidades e as possibilidades de intervenções sobre os riscos ${ }^{5-7}$.

A incipiência de informações importantes sobre a população dos locais de implantação pode ser um mecanismo de omissão de um dado importante para a análise dos potenciais impactos negativos, percebidos após a implantação efetiva do empreendimento. Assim, os impactos negativos são subestimados no momento do licenciamento, quando poderiam ter utilizado modelos analíticos de construção de cenários prospectivos de situações de perigo ${ }^{5}$.

O que se observou, na análise do tema saúde nos EIAs, foi o escamoteamento de riscos previsíveis, por meio da utilização de informações desconectadas das relações socioambientais no território de implantação das refinarias.

A ecologia de saberes valoriza a produção de informações construídas junto com os sujeitos sociais potencialmente atingidos e favorece a valorização da história de experiências de polos industriais similares em territórios contaminados marcados por injustiça ambiental ${ }^{14}$. Dessa maneira, as experiências vivenciadas servem como referências para que não se reproduzam violências e injustiças ${ }^{33}$.

No Quadro 3, estão os resultados sobre os custos socioambientais. Nota-se que não são devidamente identificados e dimensionados. Há a não-internalização dos custos provocados por: reassentamento das pessoas, desterritorialização, ocupação desordenada do território, perda dos modos de vida, pressão sobre os sistemas de seguridade social, intensificação do tráfego automotivo, e pelo tráfego de produtos perigosos, violência, racionamento do abastecimento de água, déficit na rede de esgoto, e problemas com o destino final de resíduos ${ }^{13}$.

Assim, há externalização dos custos para a população local, e, também, para a sociedade como um todo, já que as externalidades negativas sobre a saúde, no médio e longo prazo, recaem sobre o SUS.

Como proposta alternativa, ao modelo tradicional de análise dos custos socioambientais, preconizase a aplicação de abordagens integradoras para analisar danos ambientais, consequências para os grupos sociais vulneráveis ${ }^{6,7}$.

A ecologia de saberes para a elaboração dos EIAs toma a equidade social de gênero, de raça e de geração como orientadora do estabelecimento de medidas preventivas, adequadas ao contexto complexo da indústria do refino do petróleo ${ }^{10}$.

Do mesmo modo, os processos ecológicos, tecnológicos e culturais são articulados para o desenvolvimento humano nos territórios ${ }^{23}$, reconhecendo os processos que refletem valores e interesses sociais diversos, bem como, relações de poder conflitantes que se constituem na expressão histórica das relações sociais e das formas de reprodução social ${ }^{31}$.

A perspectiva é a de que as informações contribuam para dar voz aos grupos afetados pelos impactos, mesmo contrariando os projetos hegemônicos ${ }^{34,35}$. Do modo como têm sido elaborados os EIAs, aos povos, comunidades tradicionais e organizações da sociedade civil, são negadas informações sobre os potenciais impactos, inviabilizando a discussão sobre as alternativas oriundas do conhecimento dos povos, das potencialidades sociais e tecnológicas ${ }^{5-7}$.

De acordo com Morgan ${ }^{35}$, é fundamental, para o processo decisório, envolver pessoas socialmente comprometidas e esclarecidas sobre os conceitos, objetivos e implicações atuais e futuras do licenciamento ambiental, sendo fundamental que as mesmas conheçam as convenções, legislações e o conceito de desenvolvimento sustentável. 
Os saberes populares e tradicionais são desvalorizados e considerados atrasados, no entanto, foram eles que garantiram a vida por contribuírem para a manutenção dos ecossistemas, enquanto os da "modernidade", com menos de trezentos anos, colocam a sobrevivência do planeta em perigo $0^{33,36-38}$.

Nesse contexto, a perspectiva para a ecologia de saberes valoriza a intersubjetividade, com vista a respeitar o direito das populações locais e da sociedade, de não aceitar, em seus territórios, determinados processos produtivos que, além de causarem danos à saúde, representam mudanças na história, cultura e nos modos de sobrevivência ${ }^{10,37}$.

Torna-se necessário um ponto de equilíbrio entre os projetos de infraestrutura dos governos e o respeito aos direitos humanos e constitucionais dos povos tradicionais. O papel dos ElAs é evitar que empreendimentos produzam situações que atinjam povos e comunidades que vivem do manejo equilibrado dos bens ambientais ${ }^{10,37}$.

Quadro 3. Custos socioambientais nos EIAs, a análise crítica ao modelo tradicional de construção de conhecimento dos EIAs e as perspectivas alternativas para a ecologia de saberes, Brasil, 2014

\begin{tabular}{|c|c|c|c|}
\hline Categoria & $\begin{array}{l}\text { Conteúdos temáticos } \\
\text { extraídos dos EIA }\end{array}$ & $\begin{array}{l}\text { Análise crítica ao modelo } \\
\text { tradicional de construção de } \\
\text { conhecimento dos EIAs }\end{array}$ & $\begin{array}{l}\text { Perspectivas alternativa } \\
\text { para a ecologia de saberes }\end{array}$ \\
\hline $\begin{array}{l}\text { Custos socio- } \\
\text { ambientais }\end{array}$ & $\begin{array}{l}\text { Desconsidera a } \\
\text { aplicabilidade } \\
\text { de abordagens } \\
\text { sócioantroplógicas e as } \\
\text { categorias de raça, etnia, } \\
\text { cor, gênero, geração etc.; } \\
\text { Ausência de previsão } \\
\text { dos custos para os } \\
\text { empreendedores pelo } \\
\text { aumento da poluição; } \\
\text { Desconsideração dos } \\
\text { custos por: perda da } \\
\text { cultura; da ocupação } \\
\text { desordenada do solo; do } \\
\text { aumento da violência/ } \\
\text { criminalidade e da } \\
\text { prostituição; de novos } \\
\text { danos à saúde da } \\
\text { população; da pressão } \\
\text { sobre os serviços locais } \\
\text { de habitação, saúde, } \\
\text { educação, assistência } \\
\text { social. }\end{array}$ & $\begin{array}{l}\text { A omissão dos custos socioambientais } \\
\text { parece uma tendência dos } \\
\text { empreendedores em não assumir os } \\
\text { custos; } \\
\text { Os custos reais não são revelados, } \\
\text { que pode ser uma estratégia para } \\
\text { externalizar a responsabilidade; } \\
\text { Não há a possibilidade de } \\
\text { conclusão referente aos aspectos } \\
\text { socioeconômicos; } \\
\text { Desconsideram os grupos sociais } \\
\text { e populacionais vulneráveis pelos } \\
\text { impactos. } \\
\text { Faltam estudos de cenários, a } \\
\text { respeito da população atraída pela } \\
\text { e para implantação, operação ou } \\
\text { modernização e a repercussão para a } \\
\text { população residente; } \\
\text { Ausência dos aspectos relacionados à } \\
\text { exportação de riscos entre regiões. }\end{array}$ & $\begin{array}{l}\text { Utilização de método sócioantropológico } \\
\text { que revele os valores econômicos } \\
\text { relacionados aos impactos; } \\
\text { Responsabilização os empreendedores } \\
\text { pelos custos diretos e indiretos para a } \\
\text { descontaminação ambiental e assistência } \\
\text { à saúde em situações de exposição a } \\
\text { poluentes químicos, desastres e acidentes } \\
\text { industriais ampliados; } \\
\text { Desenvolvimento de estudos de cenários } \\
\text { do fluxo migratório, os danos ambientais e } \\
\text { as consequências para os grupos sociais e } \\
\text { populacionais vulneráveis; } \\
\text { Análise ampliada dos riscos apontando as } \\
\text { medidas mitigadoras ou a aplicação do } \\
\text { princípio da precaução e sua aplicação } \\
\text { com base em dois pressupostos: a } \\
\text { possibilidade de que condutas humanas } \\
\text { causem danos coletivos vinculados a } \\
\text { situações catastróficas que podem afetar } \\
\text { o conjunto de seres vivos; e a falta de } \\
\text { evidência científica (incerteza) a respeito } \\
\text { da existência do dano temido. }\end{array}$ \\
\hline
\end{tabular}

Em relação à saúde (Quadro 4), verificou-se que esse conceito, nos EIAs, reproduz a ideia de ausência de doença. É reproduzida uma concepção baseada numa visão biologicista, individual, centrada na perspectiva de causalidade linear, deixando de considerar as inter-relações existentes entre adoecer e morrer com os aspectos socioculturais e ambientais, nos contextos de vida e de trabalho ${ }^{5-7}$.

A teoria da unicausalidade é fortemente evocada (todo acidente ou doença tem uma causa, e cada causa determina um único acidente ou doença). Não emergem considerações ao SUS, nem aos seus 
princípios e diretrizes. Não concebem a promoção da saúde e a qualidade de vida, e desconsideram as Redes de Atenção Integral em Saúde ${ }^{6,7}$.

Pode-se afirmar que a explicação dos fenômenos se dá de forma reduzida e isolada. As doenças são concebidas como geradas por agentes patogênicos, e não como resultantes da determinação social da saúde ${ }^{31}$.

Em outra direção, a perspectiva da ecologia de saberes incorpora o conceito de saúde como um direito para a realização da vida. Por isso, saúde significa: ter condições adequadas de moradia, possibilidade de trabalhar sem adoecer por exposição a situações de riscos no ambiente de trabalho, ter acesso a espaços saudáveis para lazer e práticas de vida saudável, alimentação saudável e de fácil acesso, poder desfrutar do ar puro, de clima adequado.

Para a ecologia de saberes, saúde é interdependente: da sustentabilidade ecológica, da democracia, da garantia dos direitos humanos, da promoção da justiça social, todos os aspectos responsáveis pela produção da qualidade de vida.

Concorda-se com lanni ${ }^{39}$, ao considerar saúde como resultado de processos e interações que resultam em mudanças e adaptações constantes, variando segundo os tempos históricos e sociais, em inter-relação com a dinâmica da natureza.

Quadro 4. Aspectos de saúde nos EIAs, a análise crítica ao modelo tradicional de construção de conhecimento dos EIAs e as perspectiva alternativas para a ecologia de saberes, Brasil, 2014

\begin{tabular}{|c|c|c|c|}
\hline Categoria & $\begin{array}{l}\text { Conteúdos temáticos } \\
\text { extraídos dos EIA }\end{array}$ & $\begin{array}{l}\text { Análise crítica ao modelo } \\
\text { tradicional de construção de } \\
\text { conhecimento dos EIAs }\end{array}$ & $\begin{array}{l}\text { Perspectivas alternativa } \\
\text { para a ecologia de saberes }\end{array}$ \\
\hline $\begin{array}{l}\text { Aspectos } \\
\text { de Saúde }\end{array}$ & $\begin{array}{l}\text { Saúde como ausência de } \\
\text { doença numa concepção } \\
\text { baseada na unicausalidade em } \\
\text { que todo acidente ou doença, } \\
\text { tem uma única causa e cada } \\
\text { causa determina um único } \\
\text { acidente ou doença. } \\
\text { Não consideram a existência } \\
\text { do Sistema Único de Saúde, } \\
\text { seus princípios e diretrizes, nem } \\
\text { consideram a Promoção da } \\
\text { Saúde e a qualidade de vida. } \\
\text { Desconsideram as Redes de } \\
\text { Atenção Integral de Saúde. }\end{array}$ & $\begin{array}{l}\text { Os acidentes são explicados como } \\
\text { culpa do trabalhador (ação isolada } \\
\text { do indivíduo), o ato inseguro; as } \\
\text { doenças como resultantes específicas } \\
\text { da atuação de agentes patogênicos } \\
\text { sobre o organismo; } \\
\text { Abordagem biologicista, individual, } \\
\text { centrada no conhecimento médico, } \\
\text { na exposição a agentes externos na } \\
\text { concepção linear de causa-efeito. } \\
\text { A saúde não está relacionada aos } \\
\text { determinantes socioambientais } \\
\text { envolvendo as refinarias }\end{array}$ & $\begin{array}{l}\text { Saúde garantida mediante políticas } \\
\text { públicas saudáveis que promovem o } \\
\text { bem-estar, a qualidade de vida, que } \\
\text { respeitam o lugar, as culturas e as } \\
\text { histórias dos povos. } \\
\text { Compreensão de que a saúde } \\
\text { é determinada pelas condições } \\
\text { econômicas, sociais e ambientais, } \\
\text { consequentemente, pelo modelo de } \\
\text { desenvolvimento adotado pelo país. } \\
\text { Saúde interdependente da } \\
\text { sustentabilidade ecológica, da } \\
\text { democracia, direitos humanos, da } \\
\text { justiça social e qualidade de vida. }\end{array}$ \\
\hline
\end{tabular}

\section{Considerações finais}

Os resultados apontam para os potenciais da ecologia de saberes como proposta alternativa ao modo tradicional de elaboração de EIAs de refinarias no Brasil, superando-se as ausências de aspectos importantes para a proteção da saúde.

Essa perspectiva favorece a maior integração de profissionais, conceitos, estratégias e métodos de produção de conhecimento sobre saúde coletiva na elaboração de ElAs.

Buscou-se contribuir com a discussão em torno do valor dos ElAs e a importância da ecologia de saberes como proposta emancipatória, integradora e alternativa ao modo hegemônico de produção de conhecimento técnico-científico. 
Este artigo não esgota as possibilidades de aplicabilidade da ecologia de saberes em outras dimensões da saúde coletiva, sendo necessário o desenvolvimento de pesquisas empíricas, sobretudo, envolvendo os movimentos sociais.

As discussões apontam para aspectos fundamentais para profissionais que têm a democracia como um valor na atividade e produção acadêmica, sendo a elaboração dos EIAs um momento importante para a produção compartilhada de conhecimento a partir da participação social.

\section{Colaboradores}

Os autores Silva JM e Augusto LGS participaram, igualmente, da elaboração do artigo, de sua discussão e redação, e da revisão do texto. Gurgel IDG participou da revisão bibliográfica, de discussões e revisão do texto.

\section{Referências}

1. Parecer jurídico. Paulo Affonso Leme Machado. Competência da Saúde na área de saúde ambiental: análise sobre as necessidades de inclusão de mecanismos legais complementares aos já existentes nas Leis 8.080/90 e 8.142/90. Brasília (DF); 2004. p. $1-70$.

2. Cartilha de licenciamento ambiental. Brasília (DF): Tribunal de Contas da União; 2007.

3.Cancio JA. Inserção das questões de saúde no estudo do impacto ambiental [dissertação]. Brasília (DF): Universidade Católica de Brasília; 2008.

4. Silva JM, Gurgel AM, Gurgel IDG, Augusto LGS. A inter-relação saúde, trabalho e ambiente no licenciamento da refinaria do nordeste. Tempus Act Saude Colet. 2009; 4(4):72-83.

5. Gurgel AM, Medeiros ACLV, Alves PC, Silva JM, Gurgel IGD, Augusto LGS. Framework dos cenários de risco no contexto da implantação de uma refinaria de petróleo em Pernambuco. Cienc Saude Colet. 2009; 14(6):2027-38.

6. Silva JMS, Augusto LGS, Gurgel IDG. Saúde do trabalhador nos estudos de impactos de refinarias de petróleo. Cad Saude Colet. 2013; 21(3):325-31.

7. Silva JM, Santos MOS, Augusto LGS, Gurgel IDG. Desenvolvimento sustentável e saúde do trabalhador nos estudos de impacto ambiental de refinarias no Brasil. Saude Soc. 2013; 22(3):687-700.

8. Rigotto RM, Alió MA. Indústria, ambiente e saúde: licenciamento ambiental na Europa e no Brasil. Rev Mercator. 2003; 2(4):77-86.

9. Rigotto RM. Inserção da saúde nos estudos de impacto ambiental: o caso de uma termelétrica a carvão mineral no Ceará. Cienc Saude Colet. 2009;14(6):2049-59.

10. Garzon LFN. Relatório síntese: projeto avaliação de equidade ambiental como instrumento de democratização dos procedimentos de avaliação de impactos de projetos de desenvolvimento. Rio de Janeiro: ETTERN; 2011. 
11. Portaria conjunta Ministério do Meio Ambiente e Instituto Brasileiro de Meio Ambiente e Recursos Naturais Renováveis, n. 259, de 7 de agosto de 2009. Dispõe sobre a inclusão no Estudo e Relatório de Impacto Ambiental de capítulo específico sobre as alternativas de tecnologias mais limpas para reduzir os impactos na saúde do trabalhador e no meio ambiente, incluindo poluição térmica, sonora e emissões nocivas ao sistema. Diário Oficial da União. 13 Ago 2009. Seção 1:192.

12. Lei Complementar no 140, de 8 de dezembro de 2011. Fixa normas, nos termos dos incisos III, VI e VII do caput e do parágrafo único do art. 23 da Constituição Federal, para a cooperação entre a União, os Estados, o Distrito Federal e os municípios nas ações administrativas decorrentes do exercício da competência comum relativas à proteção das paisagens naturais notáveis, à proteção do meio ambiente, ao combate à poluição em qualquer de suas formas e à preservação das florestas, da fauna e da flora; e altera a Lei no 6.938, de 31 de agosto de 1981. Diário Oficial da União. 9 Dez 2011. Seção 1:3.

13. Sevá Filho AO. Problemas intrínsecos e graves da expansão mineral, metalúrgica, petrolífera e hidroelétrica nas Amazônias. In: Zhouri A, Laschefski K, organizadores. Desenvolvimento e conflitos ambientais. Belo Horizonte: Ed. UFMG; 2010. p. 114-47.

14. Augusto LGS. Estudo das alterações morfológicas (medula óssea) em portadores de neutropenia secundária à exposição ao benzeno [tese]. Campinas (SP): Universidade de Campinas; 1991.

15. Augusto LGS. Exposição ocupacional a organoclorados em indústria química de Cubatão-Estado de São Paulo: avaliação do efeito clastogênico pelo Teste de Micronúcleos [tese]. Campinas (SP): Universidade de Campinas; 1995.

16. Ferreira LL, Iguti AM. O trabalho dos petroleiros: perigoso, complexo, contínuo e coletivo. São Paulo: Scritta; 1996.

17. Souza CAV, Freitas CM. Perfil dos acidentes de trabalho em refinaria de petróleo. Rev Saude Publica. 2003; 36(5):576-83.

18. Freitas CM, Porto MFS, Gomes CM. Acidentes químicos ampliados: um desafio para a saúde pública. Rev Saude Publica 2001; 21(2):503-14.

19. Augusto LGS, Novaes TCP. Ação médico-social no caso do benzenismo em Cubatão, São Paulo: uma abordagem interdisciplinar. Cad Saude Publica. 1999; 15(4):729-38.

20. Mariano JB. Impactos ambientais do refino de petróleo [tese]. Rio de Janeiro (RJ): Universidade Federal do Rio de Janeiro; 2001.

21. Santos BS. Para além do pensamento abissal: das linhas globais a uma ecologia de saberes. Rev Crit Cienc Soc. 2007; 78(1):3-46.

22. Pidner FS. Diálogos entre ciência e saberes locais: dificuldades e perspectivas [dissertação]. Belo Horizonte (BH): Universidade Federal de Minas Gerais; 2010.

23. Nunes JA. O resgate da epistemologia. Rev Crit Cienc Soc. 2008; 80(1):45-70.

24. Freitas JD, Porto MF. Por uma epistemologia emancipatória da promoção da saúde. Trab Educ Saude. 2011; 9(2):179-200.

25. Giantti LL, Landin R, Toledo RF. Aplicabilidade da ecologia de saberes em saúde e ambiente e sua permeabilidade na produção acadêmica. Cienc Saude Colet. 2014; 19(10):4091-102.

26. Carneiro FF, Pignati W, Rigotto R M, Augusto LGS, Rizzolo A, Faria NMX, editores. Dossiê Abrasco: um alerta sobre os impactos dos agrotóxicos na saúde. Rio de Janeiro: EPSJV; 2015.

27. Pereira MG. Epidemiologia: teoria e prática. Rio de Janeiro: Guanabara Koogan; 2006.

28. Minayo MCS. O desafio do conhecimento: pesquisa qualitativa em saúde. Rio de Janeiro: Hucitec, Abrasco; 2013. 
29. Silva $C R$, Bobbi BC, Simão AD. O uso da análise de conteúdo como uma ferramenta para a pesquisa qualitativa: descrição e aplicação do método. Organ Rurais Agroind. 2005; 7(1):70-81.

30. Luz MT. Complexidade do campo da Saúde Coletiva: multidisciplinaridade, interdisciplinaridade, e transdisciplinaridade de saberes e práticas - análise sócio-histórica de uma trajetória paradigmática. Saude Soc. 2009; 18(2):304-11.

31. Breilh J. La determinación social de la salud como herramienta de transformación hacia una nueva salud pública (salud colectiva). Rev Fac Nac Salud Publica. 2013; 31 Supl 1:S13-S27.

32. Zhouri A. Justiça ambiental, diversidade cultural e accountability: desafios para a governança ambiental. Rev Bras Cienc Soc. 2008; 3(68):97-194.

33. Porto $M$, Pacheco T. Conflitos e injustiça ambiental em saúde no Brasil. Tempus Act Saude Colet. 2009; 4(4):26-37.

34. Borges AC. A dimensão política do atual processo de agilização do licenciamento ambiental no Brasil. Rev Gest Polit Publicas. 2013; 3(2):284-306.

35. Morgan RK. Environmental impact assessment. Dordbrecht: Kluwer Academic Publishers; 1998.

36. Gómez CM, Minayo MCS. Enfoque ecossistêmico de Saúde: uma estratégia transdisciplinar. Interfacehs. 2006; 1(1):1-19.

37. Augusto LGS, Góes L. Compreensões integradas para a vigilância da saúde em ambiente de floresta: o caso da Chapada do Araripe, Ceará, Brasil. Cad Saude Publica. 2007; 23 Sup 4:S549-S558.

38. Porto MFS, Milanez B. Eixos de desenvolvimento econômico e geração de conflitos socioambientais no Brasil: desafios para a sustentabilidade e a justiça social. Cienc Saude Colet. 2009; 14(6):1983-94.

39. Ianni AMZ. Biodiversidade e Saúde Pública: questões para uma abordagem. Saude Soc. $2005 ; 14(2): 77-88$.

Silva JM, Gurgel IGD, Augusto LGS. Salud, ecología de los saberes y estudios de impactos ambientales de refinerías en Brasil. Interface (Botucatu). 2016; 20(56):111-22.

Este artículo presenta un análisis de estudios de impactos ambientales de refinerías de petróleo. Se realizó un análisis crítico sobre la salud colectiva con el objetivo de proponer una ecología de saberes alternativa al modelo tradicional de construcción de conocimiento en el proceso de licenciamiento ambiental. Estudio cualitativo que utilizó el análisis documental para la colecta de datos y el análisis de contenido temático para el análisis de los resultados. Se verifica que en el modo tradicional hay fragmentación, reduccionismo, desarticulación conceptual, omisión de realidades complejas, silenciamiento sobre aspectos importantes para la garantía de derechos, salud y denuncia de conflictos ambientales. Se concluye que la elaboración de estudios de impactos ambientales es una oportunidad para la práctica de la ecología de los saberes por medio de la producción de conocimientos compartida con los movimientos sociales, debiendo traducirse en instrumentos de defensa de la vida, con el objetivo de acciones de salud colectiva y de protección del ambiente.

Palabras clave: Salud. Ambiente. Ecología de los saberes. Industria do petróleo. 